\title{
BMJ Open Association between soil heavy metals and fatty liver disease in men in Taiwan: a cross sectional study
}

\author{
Yen-Chih Lin, ${ }^{1}$ le-Bin Lian, ${ }^{2}$ Chew-Teng Kor, ${ }^{3}$ Chia-Chu Chang, ${ }^{4,5}$ Pei-Yuan Su, ${ }^{1}$ \\ Wan-Tzu Chang, ${ }^{2}$ Yu-Fen Liang, ${ }^{6}$ Wei-Wen Su, ${ }^{1,5}$ Maw-Soan Soon ${ }^{1}$
}

To cite: Lin Y-C, Lian I-B, Kor C-T, et al. Association between soil heavy metals and fatty liver disease in men in Taiwan: a cross sectional study. BMJ Open 2017;7: e014215. doi:10.1136/ bmjopen-2016-014215

- Prepublication history and additional material is available. To view please visit the journal (http://dx.doi.org/ 10.1136/bmjopen-2016014215).

Received 12 September 2016 Revised 14 October 2016 Accepted 25 October 2016

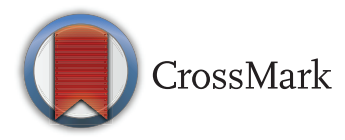

${ }^{1}$ Division of Gastroenterology, Department of Internal Medicine, Changhua Christian Hospital, Changhua, Taiwan ${ }^{2}$ Institute of Statistics and Information Science, National Changhua University of Education, Taiwan

${ }^{3}$ Internal Medicine Research Centre, Changhua Christian Hospital, Changhua, Taiwan ${ }^{4}$ Division of Nephrology, Department of Internal Medicine, Changhua Christian Hospital, Changhua, Taiwan ${ }^{5}$ School of Medicine, ChungShan Medical University, Taichung, Taiwan

${ }^{6}$ Department of Health

Evaluation, Changhua

Christian Hospital, Taiwan

Correspondence to Dr Wei-Wen Su;

vincent@cch.org.tw

\section{ABSTRACT}

Objectives: Metabolic factors are major risk factors for non-alcoholic fatty liver disease although other factors may also contribute to development of fatty liver disease. We explored the association between exposure to soil heavy metals and prevalence of fatty liver disease.

Methods: We retrospectively analysed data from patients diagnosed with fatty liver disease in 2014 at the Health Evaluation Centre of Chang-Hua Christian Hospital $(n=1137)$. We used residency data provided in the records of the Health Evaluation Centre and data for soil metal concentrations from a nationwide survey conducted by the Environmental Protection Administration of Taiwan. We studied the correlations between the severity of fatty liver disease and concentrations of soil heavy metals (arsenic, mercury, cadmium, chromium, copper, nickel, lead and zinc).

Results: The prevalence of moderate to severe fatty liver disease in our study was $26.5 \%$. Using univariate and multivariate analysis, we demonstrated that the presence of soil heavy metals was a significant risk factor for fatty liver disease in men $(\mathrm{OR} 1.83,95 \% \mathrm{Cl}$ 1.161 to $2.899, p=0.009$ ). With stratification by body mass index (BMI) and gender, lean men with a BMI $<24 \mathrm{~kg} / \mathrm{m}^{2}$ were the most susceptible to soil heavy metals (OR 5.059, 95\% Cl 1.628 to $15.728, p<0.05$ ).

Conclusions: Our study suggested a significant association between exposure to soil heavy metals and fatty liver disease in lean men.

\section{INTRODUCTION}

Viral hepatitis related to chronic hepatitis B virus or hepatitis $\mathrm{C}$ virus infection has been reported to be the leading cause of liver cirrhosis and hepatocellular carcinoma. With a decrease in the prevalence of viral hepatitis, fatty liver disease (including alcoholic liver disease and non-alcoholic fatty liver disease (NAFLD)) has emerged as an important cause of chronic liver disease. ${ }^{12}$ In Asia, the community prevalence of NAFLD was reported as $15-45 \% .^{3}$ Fatty liver disease is multifactorial with a complex aetiology

\section{Strengths and limitations of this study}

- This is the first study to demonstrate that the presence of some soil heavy metals, such as chromium, nickel and copper, is a significant risk factor for fatty liver disease in men, especially in men with a body mass index $<24 \mathrm{~kg} / \mathrm{m}^{2}$.

- In this retrospectively cross sectional study, we used the database of the Health Evaluation Centre, a single centre, to link residency data with the level of soil heavy metal concentrations provided by the government of Taiwan.

- The major limitation of our study was that the diagnosis and severity of fatty liver disease were determined by abdominal sonography and not liver biopsy. The other limitation was that there were no specimens available to directly measure levels of heavy metals in urine or serum.

which includes metabolic syndrome (Met-S), genetic factors, microbiota, etc, and is regarded as the hepatic manifestation of Met-S . ${ }^{4}$

In the past decade, a number of studies have shown deleterious effects of air pollutants on atherosclerotic cardiovascular disease and chronic obstructive pulmonary disease $^{6-8}$ There are also reports that ambient pollution, caused by air, soil and water pollutants, is an important risk factor for fatty liver disease although most of these data were obtained from animal models or in vitro studies. ${ }^{9-12}$ However, cadmium exposure was shown to have a significant impact on all cause mortality and cardiovascular disease, ${ }^{13}$ and urinary cadmium levels were shown to correlate with fasting glucose. ${ }^{14}$ Non-obese chemical workers exposed to vinyl chloride were shown to develop insulin resistance and toxicant associated steatohepatitis,${ }^{15}$ while another study reported that exposure to polychlorinated biphenyls in addition to heavy metals, such as lead and mercury, was correlated with an unexplained increase in alanine aminotransferase levels. ${ }^{16}$ Furthermore, 
recent studies have reported a positive association between exposure to ambient particulate matter and mortality in patients with diabetes mellitus. ${ }^{17}$ The correlation between exposure to air pollutants and Met-S has also been established. ${ }^{18-20}$ As fatty change in the liver is regarded as a hepatic manifestation of Met-S, it is reasonable to hypothesise that there could be a positive association between ambient pollution and fatty liver disease.

In this study, we explored the association between exposure to soil heavy metals and prevalence of fatty liver disease using a database from a nationwide survey in Taiwan.

\section{MATERIALS AND METHODS}

In this retrospective study, we analysed the database of the Health Evaluation Centre of Changhua Christian Hospital $(\mathrm{CCH})$, a tertiary referral hospital in central Taiwan. A total of 1143 individuals received conventional transabdominal sonography during their health evaluations between 6 January 2014 and 31 December 2014. Individuals younger than 20 years old and those with missing data in their profiles were excluded. We also excluded individuals with a drug history of total parenteral nutrition, or long term use of oestrogens, tamoxifen, amiodarone, sodium valproate, methotrexate or corticosteroids to reduce confounding factors. Of the 1137 individuals who were enrolled in the final analysis, $67.22 \%$ lived in Changhua County, and $32.78 \%$ came from different areas in Taiwan. All data were anonymised, and the study protocol was approved by the institutional review board of the hospital before the database was accessed (IRB No 150419).

\section{Study method}

Transabdominal sonography is the method of choice to diagnose fatty liver disease worldwide due to its accessibility and convenience. We used the transabdominal sonography data to evaluate hepatic steatosis with a traditional scoring system, which includes six main criteria: parenchymal brightness, liver to kidney contrast, deep beam attenuation, bright vessel walls and gallbladder wall definition. Based on the score, we classified the severity of fatty liver disease as follows: (1) negative ( 0 points); (2) mild ( 1 or 2 points); (3) moderate (3 or 4 points); and severe ( 5 or 6 points). We analysed all the factors which may lead to fatty liver disease.

The residential township of each individual was accessed from the database of the Health Evaluation Centre of the CCH. To clarify the association between fatty liver disease and exposure to heavy metals, we correlated the severity of fatty liver disease of each patient with the level of heavy metals in the soil of his/her residential township. The Soil Heavy Metal Spatial Distribution is based on the Environment Resource Database, established by the Taiwan Environmental Protection Administration (EPA).$^{21}$ The data for heavy metal concentrations (HMCs) in the surface farm soils
$(0 \sim 15 \mathrm{~cm})$ were obtained from a national survey in Taiwan. ${ }^{11}$ The survey included the following eight metals: arsenic (As), mercury ( $\mathrm{Hg})$, cadmium (Cd), chromium $(\mathrm{Cr})$, copper $(\mathrm{Cu})$, nickel $(\mathrm{Ni})$, lead $(\mathrm{Pb})$ and zinc $(\mathrm{Zn}) .{ }^{13}$ The total concentrations of extractable As and $\mathrm{Hg}$ in the soil were measured using the aqua regia method, while concentrations of the other six heavy metals were retrieved using the $0.1 \mathrm{~N} \mathrm{HCl}$ extraction method.

In Taiwan, heavy metal pollution, especially $\mathrm{Ni}, \mathrm{Cr}$ and $\mathrm{Cd}$, has been largely due to the fast growing number of electroplating factories in the 1970s. The EPA started a comprehensive investigation of metal concentrations in farm soil in the 1980s. Samples were taken from a network of geographically distributed sites. Most of the sampling units are from grid cell sizes of 1600 ha or less. The populated residency areas with higher concentrations were further divided into 25 ha and 1 ha. ${ }^{22}$ We obtained a value which represented the metal concentration in a certain township/precinct by averaging the results of different samples within the same township/ precinct. After excluding a few alpine areas with very small populations and a few metropolitan areas with very few farms, we obtained data for a total of 316 townships/ precincts which had measurement data for metal concentrations.

In this study, we used the concentration data based on the average of the measurements in the past 30 years. As most of the patients in the study were native local people over 30 years old, they had a similar exposure duration of more than 30 years. Therefore, their accumulated exposure to the metals was proportional to the concentration level used in our analysis.

\section{Definitions of variables}

For the purposes of this analysis, the severity of fatty liver disease was categorised as normal (negative or mild) or abnormal (moderate or severe). The categorised risk factors used in the analysis included age (cut-off points $<50,50-65,65+)$, gender (women $/$ men), body mass index (BMI) (cut-off points <24, 24-27, 27+), metabolic factors (defined as shown in reference), Met-S (yes/no), glutamic-pyruvic transaminase/alanine aminotransferase (cut-off $40 \mathrm{U} / \mathrm{L}$ ), glutamic oxaloacetic transaminase/ aspartate aminotransferase (cut-off $41 \mathrm{U} / \mathrm{L}$ ), glutamic acid transferase (cut-off $50 \mathrm{U} / \mathrm{L}$ ), low density lipoprotein cholesterol (cut-off $130 \mathrm{mg} / \mathrm{dL}$ ), hepatitis B surface antigen (yes/no), anti-hepatitis C virus (yes/no), creatinine (cut-off: men $1.2 \mathrm{mg} / \mathrm{dL}$; women $1.0 \mathrm{mg} / \mathrm{dL}$ ), bilirubin (cut-off $1.2 \mathrm{mg} / \mathrm{dL}$ ), smoking (yes/no), alcohol consumption (yes/no), betel nuts use (yes/no) and heavy metal exposure (yes/no). Met-S, according to the ATPIII definition of 2004, has five risk factors: central obesity (waist), hypertension, high density lipoprotein cholesterol, fasting glucose (AC sugar) and triglycerides. All of these risk factors are significantly associated with the degree of fatty liver disease 
$(\mathrm{p}<0.001)$, and a diagnosis of Met-S is made when three of the five risk factors are present.

The Deprivation Index score, a continuous variable which represents the socioeconomic status of a township, is comprised of the proportion of elementary occupations and the school dropout rate of students aged 15-17 years. The Deprivation Index score was obtained from the population and housing census data from the year 2000 from the Survey Research Data Archive, Academia Sinica, Taiwan. ${ }^{23}$ Based on the EPA's five category classification system for HMC, levels 1 and 2 represent no soil heavy metal pollution, level 3 represents background concentration, and levels 4 and 5 represent a level of pollution for which intensive monitoring and remedial action are needed. In this study, we used the dichotomous variable by combining levels $1-3$ as non-polluted and levels $4-5$ as polluted.

\section{Statistical methods}

Patient characteristics and dichotomising biochemistry results from laboratory data are presented as percentages. We used the $\chi^{2}$ test for categorical comparisons of data. Logistic regression analysis was performed to assess the association between ambient heavy metal exposure and fatty liver events. Confounders, including age, sex, BMI, Met-S, smoking, alcohol consumption and Deprivation Index score, were adjusted in multivariate logistic analysis to estimate OR and 95\% CI. Multivariate logistic analysis stratified by gender as well as by BMI category was performed to explore the association between gender, BMI and fatty liver disease. All statistical analyses were performed with the SAS statistical package (V.9.4 for Windows; SAS Institute, Cary, North Carolina, USA).

\section{RESULTS}

The distribution of patient demographics and clinical characteristics of the 1137 patients are presented in table 1. Mean age of the study patients was 50.72 \pm 0.35 years $(50.91 \pm 0.52$ years for men and $50.56 \pm 0.49$ years for women). About $26.5 \%$ of patients (301 of 1137) were classified as having moderate or severe fatty liver disease, and the rest were classified as mild (254) or negative (582) for fatty liver disease. A total of $74 \%$ of patients (842 of 1137) had at least one metabolic factor. Heavy metal exposure was documented in $56.48 \%$ of patients in the moderate or severe fatty liver group, and in $52.51 \%$ of patients in the negative or mild fatty liver group.

\section{Association of heavy metal exposure and fatty liver disease in men}

Gender, BMI, Met-S, glutamic-pyruvic transaminase, glutamic oxaloacetic transaminase, glutamic acid transferase, low density lipoprotein cholesterol, smoking, alcohol consumption and all metabolic factors were associated with fatty liver disease (table 1). Severe fatty disease was documented in 32\% of men (198/620) and in $20 \%$ of women $(103 / 517)$. Men were significantly more likely to have severe fatty liver disease compared with women $(p<0.001)$. Multivariate logistic regression analysis showed that BMI and Met-S were significantly associated with severe fatty liver disease in both men and women (both $\mathrm{p}<0.001$ ).

Heavy metal exposure was significantly associated with fatty liver disease in men (OR (95\% CI) 1.834 (1.161 to $2.899), \mathrm{p}=0.009)$ but not in women (OR (95\% CI) 1.058 (0.572 to 1.955), $\mathrm{p}=0.858$ ) (table 2). The classification of heavy metal levels by the EPA was based on the concentrations of the eight metals mentioned above. To explore the association of each metal with the risk of fatty liver disease, we used the concentration of each metal to replace the EPA's classification on metal, along with the other factors in table 2 for men. The adjusted OR of each metal showed a significant association for $\mathrm{Cr}, \mathrm{Ni}$ and $\mathrm{Cu}$ in men, with ORs of 1.063, 1.049 and 1.015, respectively (figure 1). Note that due to the high correlation among the metal concentration variables, two or more metals cannot be included in a model simultaneously, as this may cause severe variance inflation in regression.

\section{Association between heavy metal exposure and fatty liver disease in lean men}

Based on previous findings that lean individuals may also have fatty liver disease, we explored the role of BMI and gender in fatty liver disease. To perform separate logistic regression analyses, we stratified study patients into three BMI categories using the classification system suggested by the Ministry of Health and Welfare, Taiwan. The cut-off values for BMI recommended by our government are based on the study 'Body mass index and obesity-related metabolic disorders in Taiwanese and US whites and blacks: implications for definitions of overweight and obesity for Asians', published by the American Journal of Clinical Nutrition in 2004. ${ }^{24}$ These cut-off values were chosen because they are believed to be more suitable for residents of Taiwan. Patients were grouped as BMI $<24$ (lean individuals), $24 \leq \mathrm{BMI} \leq 27$ (overweight) and BMI $>27$ (obese). Our results showed that exposure to high levels of heavy metals and severe deprivation significantly increased the severity of fatty liver disease in lean individuals, with OR $(95 \% \mathrm{CI})$ of 2.432 (1.088 to 5.435, $\mathrm{p}=0.030$ ) and 1.324 (1.004 to $1.747, \mathrm{p}=0.047$ ), respectively (table 3 ). Metabolic syndrome increased the severity of fatty liver disease in individuals with $24 \leq \mathrm{BMI} \leq 27$ and BMI $>27$, with OR $(95 \%$ CI) of 2.912 (1.692 to 5.011, $\mathrm{p}<0.001)$ and 3.425 (1.667 to $7.040, \mathrm{p}<0.001)$, respectively. When patients were further divided by gender, exposure to high levels of heavy metals significantly increased the severity of fatty liver disease in lean men, with adjusted OR up to 5.059 (95\% CI 1.628 to $15.728, \mathrm{p}<0.05$ ) (figure 2 ).

\section{DISCUSSION}

The prevalence of NAFLD in western countries is estimated to be about 30\%, whereas non-alcoholic 
Table 1 Demographic and clinical characteristics of 1137 patients stratified by the degree of fatty liver disease

\begin{tabular}{|c|c|c|c|}
\hline & \multicolumn{3}{|c|}{ Degree of fatty liver disease } \\
\hline & Negative/mild & Moderate/severe & p Value \\
\hline Age (years) & $50.14 \pm 12.27^{*}$ & $52.34 \pm 11.48$ & \\
\hline$<50(\mathrm{n}(\%))$ & $393(47.01)$ & $124(41.20)$ & 0.051 \\
\hline 50-65 (n (\%)) & 346 (41.39) & 127 (42.19) & \\
\hline $65+(n(\%))$ & $97(11.60)$ & $50(16.61)$ & \\
\hline \multicolumn{4}{|l|}{ Gender (n (\%)) } \\
\hline Female & $414(49.52)$ & 103 (34.22) & $<0.001 \dagger$ \\
\hline Male & $422(50.48)$ & $198(65.78)$ & \\
\hline $\mathrm{BMI}\left(\mathrm{kg} / \mathrm{m}^{2}\right)$ & $23.23 \pm 2.94$ & $26.75 \pm 3.44$ & \\
\hline$<24(\mathrm{n}(\%))$ & $528(63.16)$ & $56(18.60)$ & $<0.001 \dagger$ \\
\hline $24-27(\mathrm{n}(\%))$ & $220(26.32)$ & $114(37.87)$ & \\
\hline $27+(\mathrm{n}(\%))$ & $88(10.53)$ & 131 (43.52) & \\
\hline \multicolumn{4}{|l|}{ Metabolic factors (n (\%)) $\ddagger$} \\
\hline Central obesity (waist) & $155(47.26)$ & $173(52.74)$ & $<0.001 \dagger$ \\
\hline Hypertension & $301(64.59)$ & $165(35.41)$ & $<0.001 \dagger$ \\
\hline HDL cholesterol & $270(62.50)$ & $162(37.50)$ & $<0.001 \dagger$ \\
\hline Fasting glucose & $171(52.13)$ & $157(47.87)$ & $<0.001 \dagger$ \\
\hline Triglyceride & $218(61.24)$ & $138(38.76)$ & $<0.001 \dagger$ \\
\hline Met-S§ (n (\%)) & $143(17.11)$ & $168(55.81)$ & $<0.001 \dagger$ \\
\hline $\mathrm{HBsAg} \geq 0.05 \mathrm{IU} / \mathrm{mL}(\mathrm{n}(\%))$ & $68(9.25)$ & $14(5.60)$ & 0.071 \\
\hline Anti-HCV reactive ( $\mathrm{n}(\%))$ & $25(3.01)$ & $5(1.69)$ & 0.226 \\
\hline GPT (U/L) & $24.36 \pm 17.64$ & $37.27 \pm 24.48$ & \\
\hline$>40 \mathrm{U} / \mathrm{L}(\mathrm{n}(\%))$ & $69(9.03)$ & $94(46.53)$ & $<0.001 \dagger$ \\
\hline GOT (U/L) & $24.47 \pm 10.53$ & $31.13 \pm 27.35$ & \\
\hline$>41 \mathrm{U} / \mathrm{L}(\mathrm{n}(\%))$ & $29(3.48)$ & $27(9.12)$ & $<0.001 \dagger$ \\
\hline r-GT (U/L) & $23.54 \pm 28.68$ & $38.76 \pm 57.53$ & \\
\hline$>50 \mathrm{U} / \mathrm{L}(\mathrm{n}(\%))$ & $53(6.31)$ & $46(15.28)$ & $<0.001 \dagger$ \\
\hline LDL cholesterol (mg/dL) & $116.45 \pm 32.10$ & $125.12 \pm 33.22$ & \\
\hline$>130 \mathrm{mg} / \mathrm{dL}(\mathrm{n}(\%))$ & $265(31.77)$ & $136(45.48)$ & $<0.001 \dagger$ \\
\hline Creatinine $(\mathrm{mg} / \mathrm{dL})$ & $0.80 \pm 0.39$ & $0.82 \pm 0.20$ & \\
\hline Male $>1.2 \mathrm{mg} / \mathrm{dL} ;$ female $>1.0 \mathrm{mg} / \mathrm{dL}$ (n (\%)) & $27(3.35)$ & $12(4.2)$ & 0.510 \\
\hline Bilirubin T (mg/dL) & $1.05 \pm 0.41$ & $1.04 \pm 0.35$ & \\
\hline$>1.2 \mathrm{mg} / \mathrm{dL}(\mathrm{n}(\%))$ & $222(26.56)$ & $78(25.91)$ & 0.829 \\
\hline Smoking (n (\%)) & $130(15.76)$ & $64(21.69)$ & $0.021 \dagger$ \\
\hline Alcohol consumption (n (\%)) & $166(20.24)$ & $80(27.30)$ & $0.012 \dagger$ \\
\hline Betel nuts user (n (\%)) & $25(3.06)$ & $13(4.45)$ & 0.262 \\
\hline Heavy metal exposureף (n (\%)) & $439(52.51)$ & $170(56.48)$ & $0.237 \dagger$ \\
\hline \multicolumn{4}{|c|}{$\begin{array}{l}{ }^{*} \text { Mean } \pm \text { SD. } \\
\dagger \chi^{2} \text { test, } p \text { value }<0.05 \text {. } \\
\text { †Metabolic factors are defined in the online supplementary appendix. } \\
\text { \$Met-S, metabolic syndrome, according to the definition of ATPIII } 2004 \text {. } \\
\text { ๆHeavy metal exposure: used the dichotomous variable by combining levels } 1-3 \text { as non-polluted and levels } 4-5 \text { as polluted, based on data } \\
\text { from the Environmental Protection Administration, Taiwan. } \\
\text { BMI, body mass index; GPT, glutamic-pyruvic transaminase; GOT, glutamic oxaloacetic transaminase; HBsAg, hepatitis B surface antigen; } \\
\text { HCV, hepatitis C virus; HDL, high density lipoprotein; LDL, low density lipoprotein; r-GT, glutamic acid transferase. }\end{array}$} \\
\hline
\end{tabular}

steatohepatitis affects $3-5 \%$ of the population. ${ }^{25-27}$ In fact, non-alcoholic steatohepatitis is now the second leading cause of liver transplantation in the USA. In Asia, the prevalence of fatty liver disease has also shown an upward trend over the past decade; the community prevalence of NAFLD was reported to be approximately $20 \%$ in China, 27\% in Hong Kong, and $15-45 \%$ in South Asia, South-East Asia, Korea, Japan and Taiwan. ${ }^{3}$ The prevalence of fatty liver disease (moderate to severe) in our cohort was $26.5 \%$, suggesting that the prevalence of fatty liver disease in Taiwan is comparable with that in western countries and other Asian countries.
Obesity, diabetes mellitus, hyperlipidaemia, alcohol and drugs have been shown to be risk factors for fatty liver disease. ${ }^{28}$ However, a diagnosis of fatty liver disease in the absence of these risk factors has suggested the role of additional risk factors, including genetic factors such as the PNPLA3 I148M and TM6SF2 E167K variants, ${ }^{28} 29$ an increase in body weight, distribution of body fat, high cholesterol diet, ${ }^{30}$ microbiota and even environmental factors (ie, air pollution or heavy metals).$^{9-12}$ In recent years, the term 'toxicant associated steatohepatitis (TASH)' has been used to describe fatty liver disease unrelated to obesity or alcohol intake. ${ }^{15} 31$ 
Table 2 Multivariate logistic regression analysis for fatty liver stratified by gender

\begin{tabular}{|c|c|c|c|c|c|c|}
\hline & \multicolumn{3}{|c|}{ Men $(n=620)$} & \multicolumn{3}{|c|}{ Women $(n=517)$} \\
\hline & OR & $95 \% \mathrm{Cl}$ & p Value & OR & $95 \% \mathrm{Cl}$ & p Value \\
\hline \multicolumn{7}{|l|}{ Age } \\
\hline$<50$ & 1.000 & & & 1.000 & & \\
\hline $50-65$ & 0.784 & 0.509 to 1.207 & 0.269 & 1.429 & 0.766 to 2.667 & 0.262 \\
\hline $65+$ & 0.833 & 0.437 to 1.587 & 0.578 & 2.783 & 1.308 to 5.925 & 0.008 \\
\hline \multicolumn{7}{|l|}{ BMI } \\
\hline$<24$ & 0.327 & 0.199 to 0.536 & $<0.001$ & 0.193 & 0.103 to 0.360 & $<0.001$ \\
\hline $24-27$ & 1.000 & & & 1.000 & & \\
\hline $27+$ & 2.191 & 1.346 to 3.565 & 0.002 & 1.561 & 0.787 to 3.096 & 0.202 \\
\hline Met-S & 2.653 & 1.688 to 4.169 & $<0.001$ & 3.885 & 2.190 to 6.894 & $<0.001$ \\
\hline Smoking & 1.064 & 0.672 to 1.686 & 0.791 & 0.536 & 0.059 to 4.846 & 0.579 \\
\hline Alcohol consumption & 1.084 & 0.708 to 1.659 & 0.710 & 2.129 & 0.574 to 7.899 & 0.259 \\
\hline Deprivation & 1.140 & 0.973 to 1.336 & 0.105 & 1.033 & 0.825 to 1.293 & 0.777 \\
\hline Heavy metal exposure & 1.834 & 1.161 to 2.899 & 0.009 & 1.058 & 0.572 to 1.955 & 0.858 \\
\hline
\end{tabular}

Patients with toxicant associated fatty liver disease may have low body fat mass and no insulin resistance, suggesting a different pathway underlying the onset of fatty liver disease.

To the best of our knowledge, our study is the first to demonstrate that the presence of soil heavy metals is a significant risk factor for fatty liver disease in men, especially in men with a BMI $<24$. On the other hand, Met-S is a significant risk factor for fatty liver disease in overweight and obese subjects, regardless of gender. In our study, we used sonography data to demonstrate that the concentration of heavy metals in farm soil was associated with the severity of fatty liver disease. Farm soil can be regarded as both an emitter and a receiver of environmental toxins. As an emitter, the soil may release toxins to affect crops, groundwater and air; as a receiver, it reflects the amount of toxin residuals which settle onto the soil, regardless of whether these originated in the air

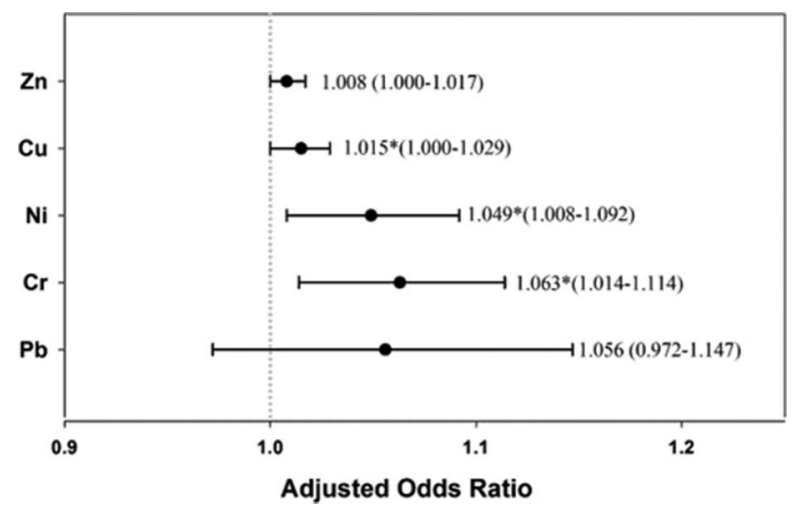

Figure 1 Adjusted OR of soil heavy metals in fatty liver disease in men. Adjusted OR $(95 \% \mathrm{Cl})$ was calculated using the concentration of each metal. Note that $\mathrm{Cr}, \mathrm{Ni}$ and $\mathrm{Cu}$ showed a significant relationship with fatty liver disease. $\mathrm{Cr}$, chromium; Cu, copper; $\mathrm{Ni}$, nickel; $\mathrm{Pb}$, lead; $\mathrm{Zn}$, zinc. or water. The HMC in farm soil is therefore a reliable representation of the amount of heavy metal present in the environment, and of the risk of exposure to the residents in the vicinity. ${ }^{32}$

Soil HMCs have been shown to be highly correlated with the concentration of heavy metals in human blood or urine in many studies conducted from 1998 to 2006 , and people who live in areas with high concentrations of soil heavy metals have higher concentrations of serum or urinary heavy metal compared with people who live in areas where the soil HMC is low. ${ }^{33-35}$ In other words, environmental heavy metals have been linked to the concentration of heavy metals in human blood or urine. Based on this evidences, the positive relation of soil heavy metals with fatty liver disease in this study could be interpreted as the impact of heavy metals on liver tissue from the perspective of public health.

The significant association between the severity of fatty liver disease and the level of metal pollution in table 2, and the significant $\mathrm{ORs}$ for $\mathrm{Cr}, \mathrm{Ni}$ and $\mathrm{Cu}$ in figure 1, support previous reports showing that the most common pollutants in water discharged from factories include $\mathrm{Ni}$, $\mathrm{Cr}, \mathrm{Cu}$ and $\mathrm{Zn}$.

Patients with diabetes mellitus are thought to benefit from $\mathrm{Cr}$ supplementation. ${ }^{36}$ However, $\mathrm{Cr}$ has two common oxidation states, $\mathrm{Cr}$ (III) and $\mathrm{Cr}$ (VI). Cr (VI) is more hazardous than $\mathrm{Cr}$ (III), and is more often a pollutant emitted by different factories. Although the EPA does not differentiate the two forms, it is known ${ }^{37}$ that $\mathrm{Cr}$ (III) can be oxidised to $\mathrm{Cr}$ (VI) by manganese oxide in soil, and Cr (VI) can be deoxidised to Cr (III) similarly. The concentrations of $\mathrm{Cr}$ (III) and $\mathrm{Cr}$ (VI) are highly correlated in Cr (IV) polluted soil.

In this study, the OR for heavy metals in lean men was up to 5.059 while the same trend was not observed in women. This gender difference was also observed in patients with chronic kidney disease. ${ }^{38}$ One hypothesis is 
Table 3 Multivariate logistic regression analysis for fatty liver stratified by body mass index

\begin{tabular}{|c|c|c|c|c|c|c|c|c|c|}
\hline & \multicolumn{3}{|c|}{ BMI <24 $(n=584)$} & \multicolumn{3}{|c|}{$24 \leq \mathrm{BMI}<27(\mathrm{n}=334)$} & \multicolumn{3}{|c|}{$B M I \geq 27(n=219)$} \\
\hline & OR & $95 \% \mathrm{Cl}$ & $\begin{array}{l}p \\
\text { Value }\end{array}$ & OR & $95 \% \mathrm{Cl}$ & $\begin{array}{l}\mathbf{p} \\
\text { Value }\end{array}$ & OR & $95 \% \mathrm{Cl}$ & $\begin{array}{l}p \\
\text { Value }\end{array}$ \\
\hline \multicolumn{10}{|l|}{ Age } \\
\hline$<50$ & 1.000 & - & - & 1.000 & - & - & 1.000 & - & - \\
\hline $50-65$ & 1.908 & 0.915 to 3.979 & 0.085 & 0.956 & 0.532 to 1.719 & 0.881 & 0.578 & 0.279 to 1.198 & 0.141 \\
\hline $65+$ & 0.969 & 0.293 to 3.203 & 0.959 & 1.357 & 0.638 to 2.885 & 0.428 & 0.904 & 0.291 to 2.808 & 0.862 \\
\hline Gender, male & 2.232 & 1.055 to 4.723 & 0.036 & 1.074 & 0.596 to 1.935 & 0.812 & 2.234 & 1.027 to 4.862 & 0.043 \\
\hline Met-S & 2.375 & 0.933 to 6.047 & 0.070 & 2.912 & 1.692 to 5.011 & $<0.001$ & 3.425 & 1.667 to 7.04 & $<0.001$ \\
\hline Smoking & 0.913 & 0.326 to 2.561 & 0.863 & 0.995 & 0.466 to 2.122 & 0.989 & 0.565 & 0.242 to 1.322 & 0.188 \\
\hline Alcohol consumption & 1.152 & 0.452 to 2.938 & 0.767 & 1.242 & 0.633 to 2.437 & 0.529 & 0.975 & 0.427 to 2.229 & 0.953 \\
\hline Deprivation & 1.324 & 1.004 to 1.747 & 0.047 & 1.121 & 0.907 to 1.385 & 0.291 & 1.028 & 0.793 to 1.331 & 0.836 \\
\hline $\begin{array}{l}\text { Heavy metal } \\
\text { exposure }\end{array}$ & 2.432 & 1.088 to 5.435 & 0.030 & 1.124 & 0.623 to 2.029 & 0.699 & 1.404 & 0.656 to 3.007 & 0.382 \\
\hline
\end{tabular}

that sex hormones, such as oestrogen, have antiinflammatory and immunomodulatory effects and could function as a protective factor by reducing oxidative stress and preventing the progression to fatty liver. This is evidenced by the high frequency of newly developed fatty liver disease after the use of tamoxifen by patients with breast cancer. ${ }^{39}$ On the other hand, anabolic androgenic steroids have been reported to be possible new risk factors for TASH, and the gender difference may be due to the protective effect of oestrogen and the toxic effect of androgens. Finally, based on the different trends among the different BMI groups shown in table 3 and figure 2, we suggest that the effect of the heavy metals could be masked by metabolic factors in the overweight

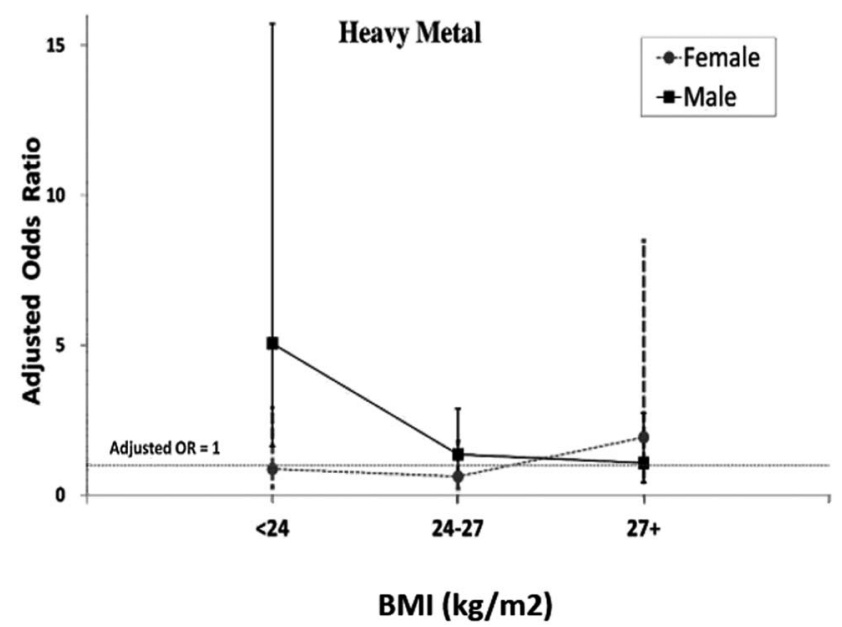

Figure 2 Adjusted OR of soil heavy metals in fatty liver disease by both gender and body mass index (BMI). When we further divided subjects by gender and BMI, the data suggested that exposure to high levels of heavy metals increased the severity of fatty liver disease only in lean males, with adjusted OR up to 5.059 (95\% Cl 1.628 to 15.728 ; $\mathrm{p}<0.05)$. or obese groups. Furthermore, as body fat itself has a favourable effect on higher metabolic reserves and sequestration of toxin, it is possible that the effect of heavy metals can only be observed in lean individuals. ${ }^{38} 40$

In summary, soil heavy metals are significantly correlated with fatty liver disease, especially in lean men. The best way to explain this phenomenon is that because several competing factors, including obesity and Met-S, which were identified in this cohort, could mask the effect of soil heavy metals, and a protective effect of oestrogen may be present in women, the contribution of heavy metal exposure may be best identified in this lean male subgroup due to the absence of those confounders.

\section{Limitations}

Our study had several limitations. Firstly, some covariates (eg, alcohol consumption, smoker or non-smoker) were self-reported, and it was difficult to obtain a precise drug history from the record; thus recall bias is inevitable. However, as our goal was to determine the effect of soil heavy metals on fatty liver disease, this bias should have had no effect on the statistical results. In fact, most of our subjects who had a history of alcohol consumption were light drinkers. Secondly, the severity of fatty liver disease was evaluated by abdominal sonography and not liver biopsy, and it is not clear whether the fatty change in the liver reflected 'true fatty liver' or deposition of heavy metals in liver parenchyma. Interestingly, using the newly developed Framingham Steatosis Index, which is an alternative evaluation tool for fatty liver disease, we found that heavy metal exposure was also positively correlated with the Framingham Steatosis Index in men with a $\mathrm{BMI}<24$, making our result more convincing. ${ }^{41}$ Thirdly, as the three metals significantly associated with fatty liver were highly correlated, it is not possible to determine which heavy metal plays the most important role in the development of fatty liver disease. 
Furthermore, our study subjects received health evaluations at the $\mathrm{CCH}$, and most were employees of the company. Employers must provide health examinations to employees under the Taiwanese law 'Labour Safety and Health Act'. Hence our study subjects were highly representative of the general population. Although some of our study subjects came from different areas in Taiwan, more than half (67.22\%) resided in Changhua County. The ethnic distribution (Chinese and aboriginal ratio) and other factors such as prevalence of smoking and deprivation in Changhua County rank in the middle among the 23 counties in Taiwan, making the study sample highly representative of the general population of Taiwan. However, as the majority of Taiwan's population is of Chinese ethnicity, the findings of this study may not be applicable to populations of other ethnic backgrounds, and further studies with larger sample sizes should be conducted in the future.

\section{CONCLUSION}

Our results suggested that higher exposure to soil heavy metals was associated with a higher severity of fatty change in men. The risk was higher in men with a BMI $<24$. Among the heavy metals, $\mathrm{Cr}, \mathrm{Ni}$ and $\mathrm{Cu}$ were highly correlated with fatty liver disease. According to this study, we need to be aware of the possibility of exposure to environmental heavy metals in lean men with unexplained fatty liver disease.

Acknowledgements We would like to thank the staff of the Changhua Christian Hospital Department of Health Evaluation who provided professional advice in our academic seminars.

Contributors W-WS and I-BL designed the research. Y-CL, I-BL, W-TC, C-TK and P-YS conducted the research. I-BL, W-TC, C-TK and Y-FL analysed the data. Y-CL and I-BL wrote the paper. C-CC and M-SS had primary responsibility for the final content. All authors read and approved the final manuscript.

\section{Competing interests None declared.}

Ethics approval The study was approved by the institutional review board of Changhua Christian Hospital (IRB No 150419).

Provenance and peer review Not commissioned; externally peer reviewed.

Data sharing statement No additional data are available.

Open Access This is an Open Access article distributed in accordance with the Creative Commons Attribution Non Commercial (CC BY-NC 4.0) license, which permits others to distribute, remix, adapt, build upon this work noncommercially, and license their derivative works on different terms, provided the original work is properly cited and the use is non-commercial. See: http:// creativecommons.org/licenses/by-nc/4.0/

\section{REFERENCES}

1. El-Serag HB. Hepatocellular carcinoma: recent trends in the United States. Gastroenterology 2004;127(5 Suppl 1):S27-34.

2. Charlton M. Cirrhosis and liver failure in nonalcoholic fatty liver disease: molehill or mountain? Hepatology 2008;47:1431-3.

3. Farrell GC, Wong VW, Chitturi S. NAFLD in Asia--as common and important as in the West. Nat Rev Gastroenterol Hepatol 2013;10:307-18.

4. Marchesini G, Bugianesi E, Forlani G, et al. Nonalcoholic fatty liver, steatohepatitis, and the metabolic syndrome. Hepatology 2003;37:917-23.
5. Schaffner F, Thaler H. Nonalcoholic fatty liver disease. Prog Liver Dis 1986;8:283-98.

6. Zhang $\mathrm{H}$, Jiang YF, He SM, et al. Etiology and prevalence of abnormal serum alanine aminotransferase levels in a general population in Northeast China. Chin Med J 2011;124:2661-8.

7. Son JY, Lee JT, Kim KH, et al. Characterization of fine particulate matter and associations between particulate chemical constituents and mortality in Seoul, Korea. Environ Health Perspect 2012;120:872-8.

8. Brunekreef B, Beelen R, Hoek G, et al. Effects of long-term exposure to traffic-related air pollution on respiratory and cardiovascular mortality in the Netherlands: the NLCS-AIR study. Res Rep Health Eff Inst 2009 Mar;(139):5-71; discussion 73-89.

9. Tan $\mathrm{HH}$, Fiel MI, Sun Q, et al. Kupffer cell activation by ambient air particulate matter exposure may exacerbate non-alcoholic fatty liver disease. J Immunotoxicol 2009;6:266-75.

10. Zheng Z, Xu X, Zhang X, et al. Exposure to ambient particulate matter induces a NASH-like phenotype and impairs hepatic glucose metabolism in an animal model. $J$ Hepatol 2013;58:148-54.

11. Hyder O, Chung M, Cosgrove D, et al. Cadmium exposure and liver disease among US adults. J Gastrointest Surg 2013;17:1265-73.

12. Polyzos SA, Kountouras J, Deretzi G, et al. The emerging role of endocrine disruptors in pathogenesis of insulin resistance: a concept implicating nonalcoholic fatty liver disease. Curr Mol Med 2012;12:68-82.

13. Kelishadi R, Askarieh A, Motlagh ME, et al. Association of blood cadmium level with cardiometabolic risk factors and liver enzymes in a nationally representative sample of adolescents: the CASPIAN-III study. J Environ Public Health 2013;2013:142856.

14. Schwartz GG, Il'yasova D, Ivanova A. Urinary cadmium, impaired fasting glucose, and diabetes in the NHANES III. Diabetes Care 2003;26:468-70.

15. Cave M, Falkner KC, Ray M, et al. Toxicant-associated steatohepatitis in vinyl chloride workers. Hepatology 2010;51:474-81.

16. Cave M, Appana S, Patel M, et al. Polychlorinated biphenyls, lead, and mercury are associated with liver disease in American adults: NHANES 2003-2004. Environ Health Perspect 2010;118:1735-42.

17. Puett RC, Hart JE, Schwartz J, et al. Are particulate matter exposures associated with risk of type 2 diabetes? Environ Health Perspect 2011;119:384-9.

18. O'Neill MS, Veves A, Zanobetti A, et al. Diabetes enhances vulnerability to particulate air pollution-associated impairment in vascular reactivity and endothelial function. Circulation 2005;111:2913-20.

19. Chen JC, Schwartz J. Metabolic syndrome and inflammatory responses to long-term particulate air pollutants. Environ Health Perspect 2008;116:612-17.

20. Kim JH, Hong YC. GSTM1, GSTT1, and GSTP1 polymorphisms and associations between air pollutants and markers of insulin resistance in elderly Koreans. Environ Health Perspect 2012;120:1378-84.

21. China EPAotRo. Survey of heavy metals in the soil samples. Statistics Office of Environmental Protection Administration. Taipei: Environmental Protection Administration of the Republic of China, 1992.

22. Lin YP, Teng TP, Chang TK. Multivariate analysis of soil heavy metal pollution and landscape pattern in Changhua county in Taiwan. Landscape Urban Plann 2002;62:19-35.

23. Lee IL, Lin HC, Chiang TL. Area deprivation, socioeconomic status, and smoking behavior among male adults in Taiwan. Taiwan J Public Health 2003;22:6.

24. Pan WH, Flegal KM, Chang HY, et al. Body mass index and obesity-related metabolic disorders in Taiwanese and US whites and blacks: implications for definitions of overweight and obesity for Asians. Am J Clin Nutr 2004;Jan;79:31-9.

25. Vernon G, Baranova A, Younossi ZM. Systematic review: the epidemiology and natural history of non-alcoholic fatty liver disease and non-alcoholic steatohepatitis in adults. Aliment Pharmacol Ther 2011;34:274-85.

26. Williams CD, Stengel J, Asike MI, et al. Prevalence of nonalcoholic fatty liver disease and nonalcoholic steatohepatitis among a largely middle-aged population utilizing ultrasound and liver biopsy: a prospective study. Gastroenterology 2011;140:124-31.

27. Bedogni G, Miglioli L, Masutti F, et al. Incidence and natural course of fatty liver in the general population: the Dionysos study. Hepatology 2007;46:1387-91.

28. European Association for the Study of the Liver (EASL), European Association for the Study of Diabetes (EASD), European Association 
for the Study of Obesity (EASO). EASL-EASD-EASO Clinical Practice Guidelines for the management of non-alcoholic fatty liver disease. J Hepatol 2016;64:1388-402.

29. Kotronen A, Johansson LE, Johansson LM, et al. A common variant in PNPLA3, which encodes adiponutrin, is associated with liver fat content in humans. Diabetologia 2009;52:1056-60

30. Liu CJ. Prevalence and risk factors for non-alcoholic fatty liver disease in Asian people who are not obese. $J$ Gastroenterol Hepatol 2012;27:1555-60.

31. Schwingel PA, Cotrim HP, Salles BR, et al. Anabolic-androgenic steroids: a possible new risk factor of toxicant-associated fatty liver disease. Liver Int 2011;31:348-53.

32. Su CC, Lin YY, Chang TK, et al. Incidence of oral cancer in relation to nickel and arsenic concentrations in farm soils of patients' residential areas in Taiwan. BMC Public Health 2010;10:67.

33. Lanphear BP, Burgoon DA, Rust SW, et al. Environmental exposures to lead and urban children's blood lead levels. Environ Res 1998;76:120-30.

34. Chang FH, Wang SL, Huang YL, et al. Biomonitoring of chromium for residents of areas with a high density of electroplating factories. J Expo Sci Environ Epidemiol 2006;16:138-46.
35. Chang $\mathrm{FH}$, Wang $\mathrm{HJ}$, Wang $\mathrm{SL}$, et al. Survey of urinary nickel in residents of areas with a high density of electroplating factories. Chemosphere 2006;65:1723-30.

36. Broadhurst CL, Domenico P. Clinical studies on chromium picolinate supplementation in diabetes mellitus--a review. Diabetes Technol Ther 2006;8:677-87.

37. Bartlett RJ, James BR. Behavior of chromium in soils. Oxidation J Environ Qual 1979;8:5.

38. Huang JC, Lin HY, Lim LM, et al. Body mass index, mortality, and gender difference in advanced chronic kidney disease. PLOS ONE 2015;10:e0126668.

39. Pan HJ, Chang HT, Lee $\mathrm{CH}$. Association between tamoxifen treatment and the development of different stages of nonalcoholic fatty liver disease among breast cancer patients. J Formos Med Assoc 2015;115:411-17.

40. Lin WY, Peng CY, Lin CC, et al. General and abdominal adiposity and risk of death in HBV versus non-HBV carriers: a 10-year population-based cohort study. Medicine (Baltimore) 2016;95:e2162.

41. Long MT, Pedley A, Colantonio LD, et al. Development and validation of the Framingham steatosis index to identify persons with hepatic steatosis. Clin Gastroenterol Hepatol 2016;14:1172-80. 